\title{
Relationship of Superoxide Production to Cytoplasmic Free Calcium in Human Monocytes
}

\author{
Sean P. Scully, George B. Segel, and Marshall A. Lichtman \\ Departments of Medicine, Pediatrics, and Radiation Biology and Biophysics, University of Rochester School of Medicine, \\ Rochester, New York 14642
}

\begin{abstract}
Calcium has been proposed as an intracellular second messenger for activation of secretion, phagocytosis, and the oxidative burst of neutrophils. We have examined the role of calcium in human monocyte activation. Concanavalin A (Con A)-stimulated monocytes displayed an increment in cytoplasmic ionized calcium at $31 \pm 6 \mathrm{~s}$ and the onset of superoxide production at $61 \pm 9 \mathrm{~s}$. The increase in cytoplasmic calcium invariably preceded the onset of superoxide production. If the external calcium concentration was reduced to $<28 \mathrm{nM}$ by the addition of $10 \mathrm{mM}$ EGTA, superoxide production was not diminished at $5 \mathrm{~min}$; however, superoxide production decreased thereafter. The Con A-evoked increment in cytoplasmic ionized calcium was blunted upon the addition of EGTA and decreased further with time. Both the production of superoxide and the Con A-evoked increment in cytoplasmic ionized calcium displayed a $50 \%$ inhibition after $15 \mathrm{~min}$ of calcium depletion and were completely inhibited after $60 \mathrm{~min}$. Total cell calcium fell from 0.7 to $0.5 \mathrm{fmol} / \mathrm{cell}$, and the basal level of ionized calcium fell from 83 to $30 \mathrm{nM}$ after $60 \mathrm{~min}$. Histidine, a strong chelator of divalent cations other than calcium and magnesium, had no effect on monocyte superoxide production or on ionized calcium concentrations, indicating that EGTA inhibition was due to cell calcium depletion. In calcium-depleted cells, Con A did not evoke superoxide production until calcium was restored to the incubation medium. The restoration of calcium to Con Atreated, calcium-depleted monocytes permitted a rapid rise in the cytoplasmic ionized calcium, and the production of superoxide within $9 \mathrm{~s}$. These data suggest that an increase in ionized cytoplasmic calcium is necessary for the activation of monocyte superoxide production by $\mathrm{Con} \mathbf{A}$. The rise in ionized calcium in response to Con $A$ results, in part, from an internal redistribution of calcium, which is sufficient to permit superoxide generation.
\end{abstract}

\section{Introduction}

The antimicrobial activity of phagocytosis is primarily the result of the production of toxic oxygen radicals. A plasma membrane oxidase that reduces oxygen at the expense of NADPH is the key enzyme in the formation of superoxide, singlet oxygen, hydroxyl radicals, and hydrogen peroxide (1). The activation of the plasma membrane oxidase may be secondary to membrane depolarization (2), the activation of serine proteases (3), or an increase in cytosolic free calcium $(4,5)$. Experimental evidence

Address reprint requests to Dr. Segel, Box 777, University of Rochester Medical Center, 601 Elmwood Avenue, Rochester, NY 14642.

Received for publication 18 April 1985 and in revised form 24 December 1985 .

J. Clin. Invest.

(c) The American Society for Clinical Investigation, Inc.

$0021-9738 / 86 / 04 / 1349 / 08 \quad \$ 1.00$

Volume 77, April 1986, 1349-1356 exists for each as a second messenger in the activation sequence. The role of calcium has been based on indirect experiments that have shown a requirement for extracellular calcium (6), an increase of ${ }^{45} \mathrm{Ca}$ exchange $(5,7,8)$, and inhibition by calcium transport blockers such as 8 -( $N, N$-diethylamino)-octyl-3,4,5-trimethoxybenzoate (9), blockage by calmodulin antagonists such as trifluoperazine $(7,10)$, and by calcium-channel blockers such as nifedipine and verapamil $(10,11)$. Changes in intracellular calcium after cell activation have been measured with chlortetracycline (9), photoproteins (12), and 2-[[2-[bis [(ethoxycarbonyl ) - methyl ] amino ] - 5 - methylphenoxy ] methyl ] - 6 methoxy - 8 - [ bis [( ethoxycarbonyl ) methyl ] amino ] quinoline (Quin 2) (13). ${ }^{1}$ The accumulated evidence has not established conclusively that an increase in intracellular calcium is the trigger for oxidase activation. Increments in cytoplasmic ionized calcium can be correlated with the initiation of superoxide production evoked by some stimuli, whereas other stimuli cause similar increases in $[\mathrm{Ca}]_{\mathrm{i}}$ without initiating superoxide production $(14,15)$; thus, the calcium signal may be necessary but not sufficient to trigger activation. Our recent direct measurements of calcium exchange and $[\mathrm{Ca}]_{i}$ indicate that an internal redistribution of calcium occurs prior to the generation of oxygen radicals when monocytes are stimulated. This report examines the requirement for an increment in monocyte ionized calcium for the activation of monocyte superoxide production.

\section{Methods}

Isolation of human monocytes. Human monocytes were isolated from plateletpheresis residues using an Isopaque-Ficoll step-gradient and centrifugal elutriation, as previously described (16). Briefly, mononuclear cells were harvested from the interface of an Isopaque-Ficoll step gradient and introduced into a Beckman JE-6 elutriator (Beckman Instruments, Inc., Fullerton, CA) at a rotor speed of 2,000 rpm. The cells were loaded into the separation chamber of the elutriator rotor at a buffer flow rate of $6.25 \mathrm{ml} / \mathrm{min}$. The buffer flow rate was increased to $12.75 \mathrm{ml} / \mathrm{min}$ to allow a differential elution of lymphocytes while monocytes remained within the separation chamber. A subsequent increase in the flow rate to $33 \mathrm{ml} / \mathrm{min}$ resulted in the collection of a monocyte population of $>90 \%$ purity as judged by cell volume distribution, morphology on blood films treated with Wrights stain, and the presence of fluoride-sensitive napthyl AS-D acetate staining. The viability of separated monocytes was $>95 \%$ as judged by staining with propidium iodide.

Measurement of superoxide production. Superoxide production was quantified by measuring the reduction of ferricytochrome $c$ at $550 \mathrm{~nm}$ in a dual-beam recording spectrophotometer (Beckman Instruments, Inc.). The assay was performed in Hanks' buffered salt solution (HBSS), to which $1 \mathrm{mM} \mathrm{MgCl}$ and $10 \mathrm{mM}$ Hepes were added. Calcium was added as the chloride salt at a concentration of $1 \mathrm{mM}$ where indicated. The resulting buffer was adjusted to $\mathrm{pH} 7.3$ and the assay was performed

1. Abbreviations used in this paper: Con A, concanavalin A; Quin 2, 2 [[2-[bis[(ethoxycarbonyl)-methyl]amino]-5-methyl]-phenoxyl]methyl]-6methoxy-8-[bis-[(ethoxycarbonyl)methyl]amino] quinoline; Quin 2-AM, Quin 2-tetraacetomethoxyester. 
at $37^{\circ} \mathrm{C}$. The inclusion of superoxide dismutase in the reference cuvette assured the specificity of the reducing agent. Cytochalasin B $(5 \mu \mathrm{g} / \mathrm{ml})$ was included in the assay to enhance superoxide production in response to concanavalin A (Con A) (17). Con A was added at a concentration of $100 \mu \mathrm{g} / \mathrm{ml}$, which maximally stimulated superoxide production in monocytes under these conditions (5). A millimolar extinction coefficient of $2.1 \times 10^{4} \mathrm{~cm}^{-1}$ for the difference between the oxidized and reduced forms of cytochrome $c$ was used to calculate superoxide production.

Monocyte calcium measurement. The calcium concentration in HBSS was determined by atomic absorption spectrophotometry as previously described (18). Samples were aspirated into an acetylene-air flame and the mean absorbance was recorded at $422.7 \mathrm{~nm}$. Additions of known amounts of calcium to parallel samples were used for internal standardization.

The ionized calcium in the HBSS was measured using a Radiometer calcium-selective electrode (Radiometer, Copenhagen, Denmark). The electrode was calibrated in a $48 \mathrm{mM}$ Tris, $150 \mathrm{mM} \mathrm{NaCl}$ buffer, $\mathrm{pH} 7.3$, to which increasing amounts of calcium were added (19). The voltage measured by the calcium electrode was a logarithmic function of the added calcium in the Tris buffer. The measurements $<6 \mu \mathrm{M}$ ionized calcium are approximations read from the lower extension of the calibration line.

Total cell-associated calcium was measured by graphite furnace atomic absorption spectrophotometry, as previously described $(5,18)$. Briefly, $10^{6}$ cells were centrifuged through a silicone oil-step gradient. The cell pellet was resuspended in $1 \mathrm{ml}$ of twice-distilled water and sonicated at $40 \mathrm{~W}$ for $20 \mathrm{~s}$. Aliquots were pipetted into a graphite cuvette of the flameless atomic atomizer attached to an atomic absorption spectrophotometer (models 555 and 351, Instrumentation Laboratory Inc., Lexington, MA). The successive addition of a calcium solution of known concentration was used to standardize each determination. The inclusion of tritiated sucrose in parallel samples allowed correction for extracellular calcium that was trapped in the cell pellet, and trapped calcium accounted for $<10 \%$ of the total measurement.

Cytoplasmic ionized calcium was determined with the fluorescent probe, Quin 2, by a modification of the procedure described by Tsien (20). In brief, $5 \times 10^{7}$ cells $/ \mathrm{ml}$ were incubated at $37^{\circ} \mathrm{C}$ in the presence of $25 \mu \mathrm{M}$ Quin 2-tetraacetomethoxyester (Quin 2-AM) (Lancaster Synthesis, England) for $30 \mathrm{~min}$ in a shaking water bath. The cells were diluted with 9 vol of buffer and incubated for an additional $30 \mathrm{~min}$. The uptake of Quin 2-AM was complete at the end of this incubation as judged by the emission spectral shift from 435 to $490 \mathrm{~nm}$. The monocytes exhibited a uniform cytoplasmic distribution of Quin 2 as judged by fluorescence microscopy. Monocytes that had incorporated Quin 2 were maintained at $37^{\circ} \mathrm{C}$, and the fluorescence intensity was monitored at $492 \mathrm{~nm}$ with a chart recorder. Excitation at $340 \mathrm{~nm}$ was interrupted between readings to minimize photobleaching of the probe. Readings were made at 10-s intervals on a chart recorder, and the tracing was constructed by connecting the peaks on the chart paper. The Quin 2 fluorescence signal was calibrated to give absolute calcium concentrations as previously described (5). The cells were permeabilized with lysophosphatidylcholine $(10 \mu \mathrm{g} / \mathrm{ml})$, which initiated a massive calcium influx and allowed saturation of the probe with calcium (21). This was considered the maximal calcium-dependent fluorescence, $F_{\max }$. Subsequently, $10 \mathrm{mM}$ EGTA was added to the cuvette, and the resulting fluorescence was considered the calcium independent fluorescence, $F_{\min }$. Ionized cytoplasmic calcium was calculated according to $[\mathrm{Ca}]_{\mathrm{i}}=\left(F-F_{\min }\right) /\left(F_{\max }-F\right) \times K_{\mathrm{d}}$. A value of $116 \mathrm{nM}$ was used for the dissociation constant of the Quin 2-calcium complex (20).

Cytochalasin B was included in the superoxide assay to produce maximal superoxide production (see above). The inclusion of cytochalasin B $(5 \mu \mathrm{g} / \mathrm{ml})$ did not alter significantly the measurement of cytoplasmic ionized calcium by the Quin-2 method. In nine measurements from three populations of blood monocytes, the resting cytoplasmic ionized calcium was $87 \pm 15 \mathrm{nM}$ (mean $\pm \mathrm{SE}$ ) without and $85 \pm 17 \mathrm{nM}$ with cytochalasin B. In the same monocytes treated with $100 \mu \mathrm{g} / \mathrm{ml} \mathrm{Con} \mathrm{A,} \mathrm{the}$ ionized calcium was $153 \pm 19 \mathrm{nM}$ without and $161 \pm 19 \mathrm{nM}$ with cytochalasin B.

\section{Results}

Superoxide production in human monocytes treated with Con $A$. Exposure of human monocytes to Con A results in an oxidative burst with the liberation of oxygen radicals, including superoxide anion. In human blood monocytes incubated in HBSS with $1 \mathrm{mM}$ calcium, the rate of superoxide anion generation increased from undetectable levels to a maximum rate of $0.78 \mathrm{nmol} / 10^{6}$ cells per $\mathrm{min}$ in response to Con A (5). The maximal rate of superoxide production was observed at $100 \mu \mathrm{g} /$ $\mathrm{ml}$ Con A. The lag time, or the interval between the exposure to Con $A$ and the onset of superoxide production was $60 \mathrm{~s}$ at all Con A concentrations. When $10 \mathrm{mM} \alpha$-methyl mannoside, a competitive inhibitor of Con A binding, was added prior to Con A, no superoxide production was observed.

Times of onset of increased cytoplasmic ionized calcium and superoxide production. The resting cytoplasmic ionized calcium concentration of human monocytes was $80 \mathrm{nM}$, which increased to $180 \mathrm{nM}$ upon exposure to $100 \mu \mathrm{g} / \mathrm{ml}$ Con $\mathrm{A}$. The time from the addition of Con $A$ to the onset of the increase in cytoplasmic ionized calcium, the lag time, was compared to the lag time for superoxide production. Fig. 1 shows a comparison of these lag times in a representative monocyte population. In nine studies of human monocytes, the mean lag time for the increase in cytoplasmic ionized calcium was $31 \mathrm{~s}$ compared to a lag time for superoxide production of $61 \mathrm{~s}(P<0.01)$. Moreover, there was no overlap in the range of lag times preceding the increase in cytoplasmic calcium as compared to those preceding superoxide production.

Effect of decreased external calcium on monocyte superoxide production. The external calcium requirement for Con A-stimulated $(100 \mu \mathrm{g} / \mathrm{ml})$ superoxide production was examined by incubating monocytes in buffers with and without calcium and in the presence and absence of divalent cation chelators (Table I). The ionized calcium in $\mathrm{HBSS}$ with $1 \mathrm{mM}$ added $\mathrm{CaCl}_{2}$ was $1,000 \mu \mathrm{M}$. Omitting the calcium from the buffer decreased the ionized calcium to $6 \mu \mathrm{M}$, and the addition of $10 \mathrm{mM}$ EGTA to the HBSS containing $1 \mathrm{mM}$ calcium, decreased the ionized cal-

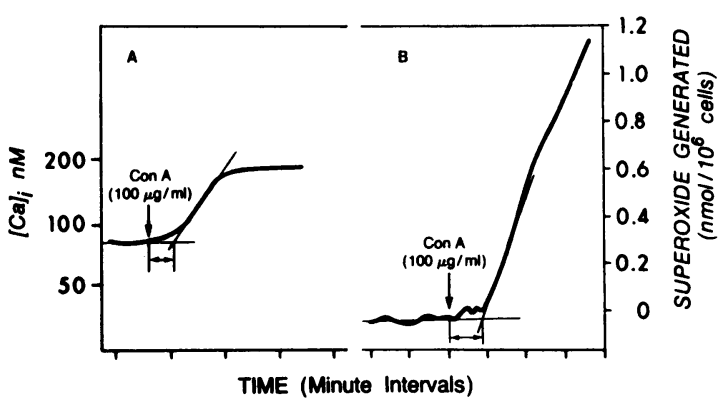

Figure 1. Lag times in monocyte activation. Human monocytes were loaded with Quin 2 and activated with Con $A(100 \mu \mathrm{g} / \mathrm{ml})$. (A) Time course of the change in cytoplasmic ionized calcium as measured by Quin 2 fluorescence. (B) Time course of superoxide production by human monocytes after Con A activation. Superoxide dismutase-inhibitable ferricytochrome $c$ reduction was used to measure monocyte superoxide production as described in the text. Cytochalasin B $(5 \mu \mathrm{g} / \mathrm{ml})$ was present in the assay to enhance superoxide production. This concentration of cytochalasin B did not effect the measurement of cytoplasmic calcium by Quin 2. (See Methods) The time scale of the chart paper measuring free calcium in a photofluorometer is slightly different from the time scale measuring superoxide anion in a spectrophotometer. The results are representative of tracings obtained from 12 monocyte populations. 
Table I. Con A-induced Superoxide

Production by Human Monocytes

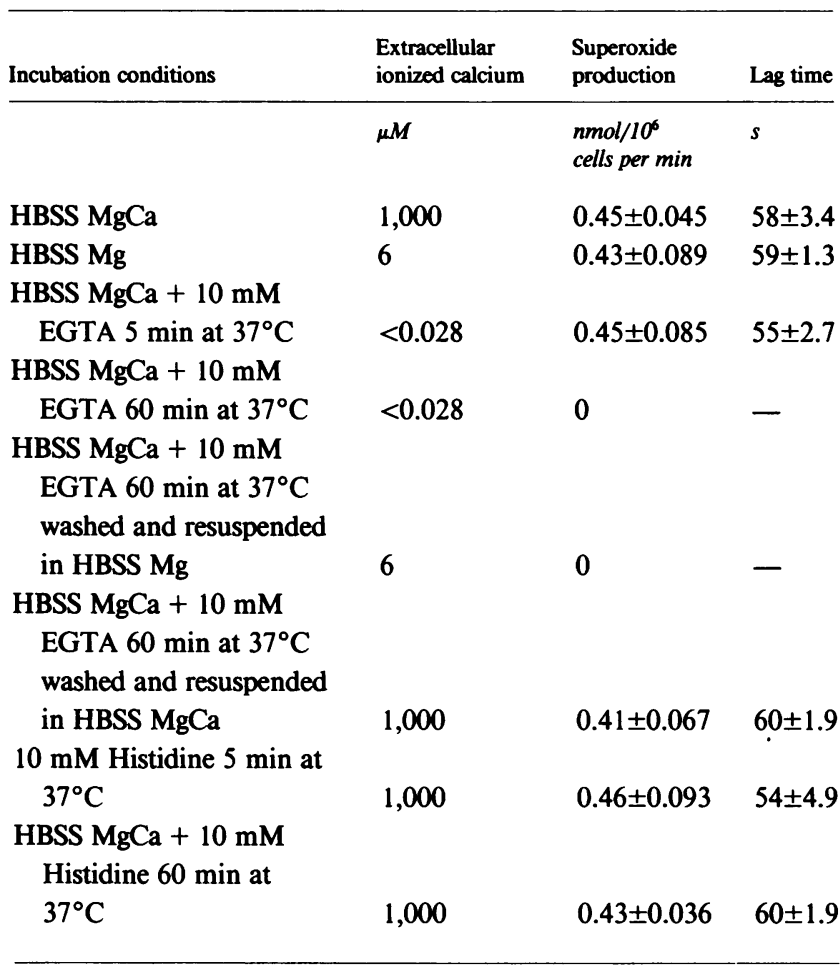

$100 \mu \mathrm{g} / \mathrm{ml}$ Con A was used to induce superoxide anion production in each of the incubation conditions shown. Data are expressed as mean \pm SE of 19 monocyte populations with EGTA and 3 monocyte populations in studies with histidine.

cium to $<0.028 \mu \mathrm{M}$. The rate of superoxide production at an ionized calcium of $1,000 \mu \mathrm{M}$ was $0.45 \mathrm{nmol} / 10^{6}$ cells per min and the lag time was $58 \mathrm{~s}$. The reduction in external ionized calcium to $6 \mu \mathrm{M}$ or to $<0.028 \mu \mathrm{M}$ made no significant difference in either the rate of superoxide production or in the lag time measured at $5 \mathrm{~min}$ (Table I). When monocytes were incubated in HBSS containing $<0.028 \mu \mathrm{M}$ ionized calcium for $60 \mathrm{~min}$, the Con A-evoked superoxide production was abolished. Superoxide production was not restored if the cells were washed and resuspended in calcium-free $(6 \mu \mathrm{M})$ buffer (Table I). However, if the cells were washed free of EGTA and $1 \mathrm{mM}$ calcium was added to the buffer prior to Con A exposure, the EGTA inhibition was reversed, and the cells produced superoxide at $0.41 \mathrm{nmol} / 10^{6}$ cells per min, which was similar to the rate of control cells, $0.45 \mathrm{nmol} / 10^{6}$ per min. Similarly, the lag time observed in the calcium-depleted and then repleted cells, $60 \mathrm{~s}$, was not significantly different from control cells, $59 \mathrm{~s}$.

Histidine displays a high affinity for divalent cations including $\mathrm{Cu}, \mathrm{Mn}, \mathrm{Zn}$, and $\mathrm{Pb}$, but in contrast to EGTA does not chelate either $\mathrm{Ca}$ or $\mathrm{Mg}$ (22). Measurements using a calcium-selective electrode indicated that $10 \mathrm{mM}$ histidine did not alter the ionized calcium concentrations in HBSS. The presence of histidine at a concentration of $10 \mathrm{mM}$, added immediately or $60 \mathrm{~min}$ prior to superoxide measurement, had no discernable effects on either the rate or the lag time of oxygen radical generation when compared to cells incubated without histidine (Table I).

Effect of calcium depletion on cytoplasmic ionized calcium: time course. In order to examine further the persistence of superoxide production that was observed after $5 \mathrm{~min}$ in buffer

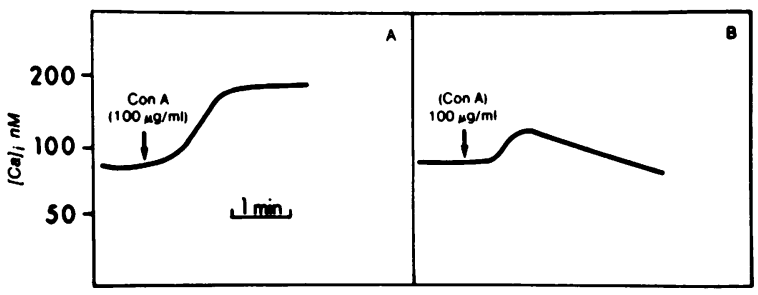

Figure 2. Effect of a decrease in external calcium on the Con A-stimulated increment in cytoplasmic ionized calcium. Monocytes from the same population were Quin 2-loaded and were suspended in either HBSS $(A)$ or HBSS $+10 \mathrm{mM}$ EGTA $(B)$ for $5 \mathrm{~min}$. Con A (100 $\mu \mathrm{g} /$ $\mathrm{ml}$ ) was then added to the cells at the time indicated by the arrows. These data are representative of measurements in nine populations of monocytes.

with EGTA (buffer ionized calcium of $<0.028 \mu \mathrm{M}$ ), we measured the monocyte cytoplasmic ionized calcium at $5 \mathrm{~min}$ of EGTA exposure. Fig. 2 compares the responses of monocyte cytoplasmic ionized calcium stimulated with Con $A$ in the presence of 1,000 $\mu \mathrm{M}$ and $<0.028 \mu \mathrm{M}$ external ionized calcium. In the former condition the cytoplasmic ionized calcium increased from 85 to $165 \mathrm{nM}$ (Fig. $2 \mathrm{~A}$ ), and the increase persisted for $>45 \mathrm{~min}$. At 5 min of incubation at $<0.028 \mu \mathrm{M}$ external calcium, Con A stimulation of monocytes caused a transient increase in ionized calcium to $115 \mathrm{nM}$ which rapidly returned to the baseline (Fig. $2 \mathrm{~B}$ ). A release of internally sequestered calcium into the cytoplasm may account for the residual increment in cytoplasmic ionized calcium.

In order to determine more fully the effect of longer periods of incubation in EGTA to promote calcium depletion, measurements of cytoplasmic ionized calcium were made during incubation in buffer containing $<0.028 \mu \mathrm{M}$ free calcium for 60 min (Fig. 3). The cytoplasmic ionized calcium decreased in unstimulated cells from $90 \mathrm{nM}$ at time 0 , to $\sim 30 \mathrm{nM}$ after $60 \mathrm{~min}$.

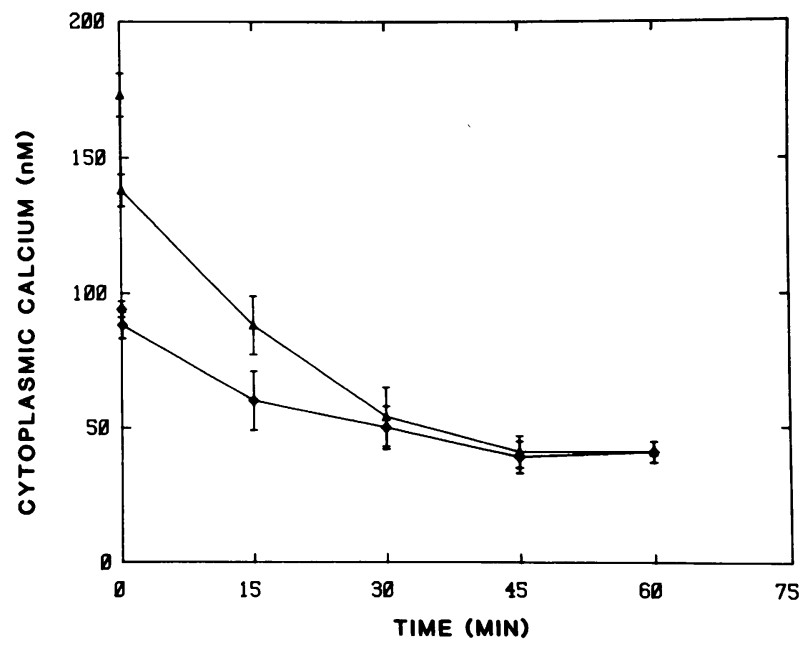

Figure 3. Effect of calcium depletion on cytoplasmic ionized calcium in resting and Con A-treated human monocytes. Monocytes were incubated at $37^{\circ} \mathrm{C}$ in $\mathrm{HBSS}$ with $1 \mathrm{mM} \mathrm{CaCl} 2$ and $10 \mathrm{mM}$ EGTA for intervals up to $60 \mathrm{~min}$. The cells were washed and resuspended in HBSS without added $\mathrm{CaCl}_{2}$ or EGTA. The resting $(\diamond)$ and Con Astimulated $(100 \mu \mathrm{g} / \mathrm{ml})(\Lambda)$ cytoplasmic ionized calcium concentrations (nanomolar) are shown. Each point represents the mean $\pm \mathrm{SE}$ of three monocyte populations. The difference between the curves represents the Con A-stimulated cytoplasmic ionized calcium at each time point. 
The Con A-stimulated cytoplasmic ionized calcium fell from 140 to $30 \mathrm{nM}$ after $60 \mathrm{~min}$. The difference between these two curves represents the Con A-induced increment in cytoplasmic ionized calcium. This increment in cytoplasmic ionized calcium decreased in the presence of external EGTA with a half time of $20 \mathrm{~min}$, and was undetectable after $60 \mathrm{~min}$. The total cellular calcium measured by graphite furnace atomic absorption had decreased from $0.72 \pm 0.11$ to $0.51 \pm 0.10 \mathrm{fmol} /$ cell during the incubation, suggesting that $\sim 30 \%$ of cell-associated calcium was removed during $1 \mathrm{~h}$ of incubation in low-calcium medium.

Effect of calcium depletion on monocyte superoxide production: time course. Monocytes that were calcium-depleted in $<0.028 \mu \mathrm{M}$ ionized calcium and resuspended in a calcium-free buffer displayed a progressive decrease in Con A-induced superoxide production (Fig. 4). Although the addition of EGTA immediately prior to Con A exposure did not significantly decrease the ability of cells to produce superoxide, incubation in EGTA for 15 min decreased the rate of superoxide production to approximately one-half of the rate observed in control cells. Calcium depletion for $60 \mathrm{~min}$ completely inhibited superoxide production in all the populations tested. This pattern of the inhibition of superoxide production was similar to that observed for the inhibition of the increment in cytoplasmic ionized calcium shown in Fig. 3.

In order to assess whether calcium depletion by an alternative method would permit Con A-stimulated superoxide production, monocytes were suspended in calcium-free HBSS with $1 \mathrm{mM}$ EGTA to insure that the free external calcium was lower than the cytoplasmic ionized calcium. In three populations of cells so treated, exposure to $500 \mathrm{nM}$ of the calcium ionophore, A23187, for $5 \mathrm{~min}$ did not initiate superoxide production, and Con A $(100 \mu \mathrm{g} / \mathrm{ml})$ produced $\sim 6 \%$ of the control rate of superoxide production. The addition of $\mathrm{CaCl}_{2}$ to the medium restored Con A-induced superoxide production. Thus, depletion of monocyte calcium stores by prolonged $(60 \mathrm{~min})$ incubation in very low calcium buffer or rapid depletion by $A 23187$ prevents Con A-stimulated superoxide production.

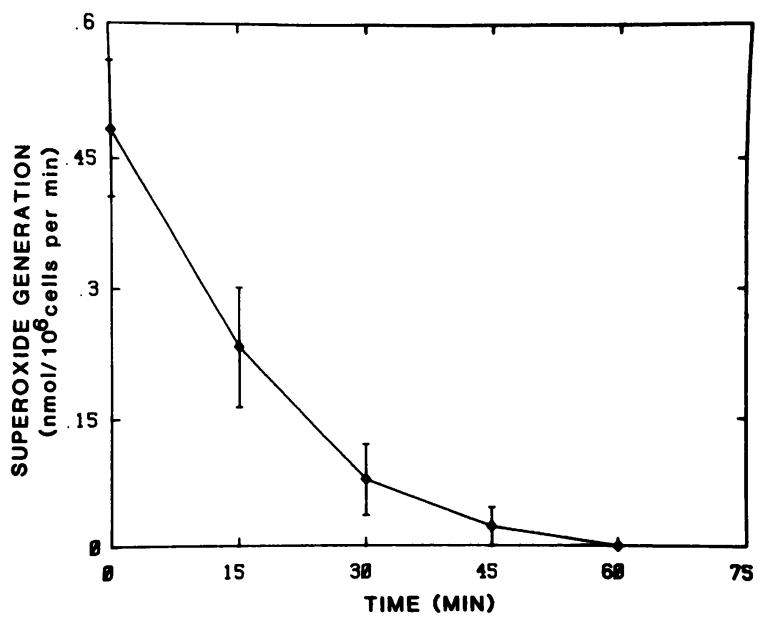

Figure 4. Effects of calcium depletion on monocyte superoxide production. Monocytes were incubated at $37^{\circ} \mathrm{C}$ in HBSS with $1 \mathrm{mM}$ $\mathrm{CaCl}_{2}$ and $10 \mathrm{mM}$ EGTA, pH 7.3, for intervals up to $60 \mathrm{~min}$. The cells were washed and resuspended in HBSS without $\mathrm{CaCl}_{2}$ or EGTA. The rate of superoxide production expressed as nanomoles $/ 10^{6}$ cells per minute in response to $100 \mu \mathrm{g} / \mathrm{ml} \mathrm{Con} \mathrm{A}$, is shown on the ordinate. Each point is the mean $\pm \mathrm{SE}$ of measurements in three monocyte populations.
Table II. Calcium-initiated Superoxide Production in Con A-stimulated Human Monocytes

\begin{tabular}{lll}
\hline Incubation conditions & Superoxide production & Lag time \\
\hline & nmol/106 cells per min & $s$ \\
HBSS Mg & 0 & - \\
HBSS Mg Con A & 0 & - \\
HBSS Mg Con A, then Ca & $0.78 \pm 0.09$ & $9 \pm 1.7$
\end{tabular}

Monocytes were calcium-depleted by incubation in HBSS with $1 \mathrm{mM}$ $\mathrm{CaCl}_{2}$ and $10 \mathrm{mM}$ EGTA, pH 7.3, for $60 \mathrm{~min}$ at $37^{\circ} \mathrm{C}$. The cells were washed and resuspended in HBSS without added calcium and exposed to Con $A(100 \mu \mathrm{g} / \mathrm{ml})$. The data represent the mean $\pm S E$ of measurements in three monocyte populations.

Restoration of monocyte superoxide production and ionized calcium content by extracellular calcium. The superoxide production in calcium-depleted monocytes could be restored by placing the cells in buffer with a millimolar calcium concentration. In these experiments, monocytes depleted of calcium and resuspended in calcium-free buffer did not respond to Con A with superoxide production, whereas calcium-depleted monocytes placed in calcium-replete buffer generated superoxide with a rate and lag time similar to monocytes that had not been calcium depleted.

In cells that had been calcium depleted and stimulated with Con A, there was no superoxide production observed (Table II). When calcium was added to these stimulated monocytes, they produced superoxide within $15 \mathrm{~s}$ (mean $9 \mathrm{~s}$ ) compared to a lag time of $\sim 60 \mathrm{~s}$ when unperturbed monocytes are exposed to Con A $(P<0.001)$ (Table II). The half-maximal rate of superoxide production in response to calcium in Con A-activated cells was observed at an ionized calcium concentration of $56 \mu \mathrm{M}$, and near-maximal rates were observed at $200 \mu \mathrm{M}$ ionized calcium (Fig. 5). Calcium-repleted cells produced superoxide at a rate of

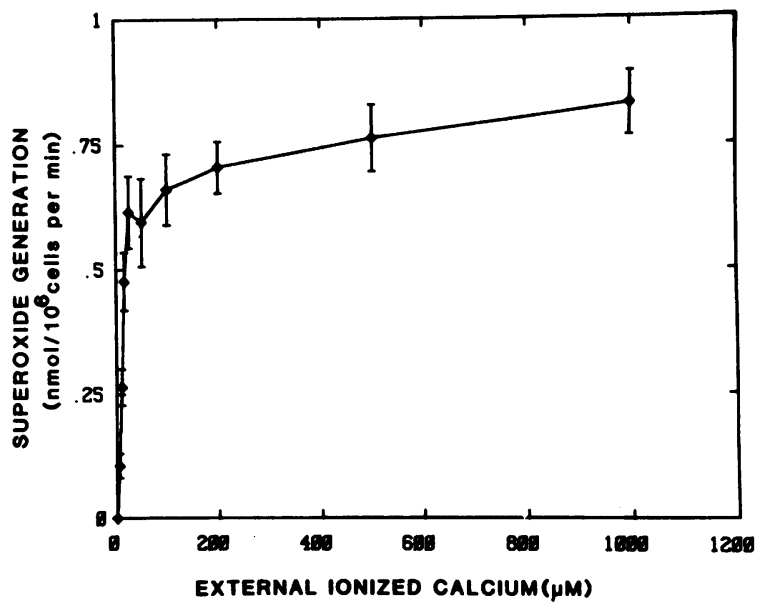

Figure 5. Concentration dependence of calcium-initiated superoxide production. Monocytes were incubated for $60 \mathrm{~min}$ at $37^{\circ} \mathrm{C}$ in HBSS with $1 \mathrm{mM} \mathrm{CaCl} 2$ and $10 \mathrm{mM}$ EGTA. The cells were washed and resuspended in $\mathrm{HBSS}$ without $\mathrm{CaCl}_{2}$ or EGTA. Aliquots of the cells were exposed to Con $A(100 \mu \mathrm{g} / \mathrm{ml})$, which caused no detectable production of superoxide. The subsequent addition of $\mathrm{CaCl}_{2}$ at the concentrations indicated resulted in superoxide production that increased with increasing external ionized calcium concentration. The rate of superoxide production is expressed as nanomoles $/ 10^{6}$ cells per minute. The data represent the mean $\pm \mathrm{SE}$ in three monocyte populations. 
$0.78 \mathrm{nmol} / 10^{6}$ cells per min (Table II), greater than in cells that were never calcium depleted, $0.48 \mathrm{nmol} / 10^{6}$ cells per min. The addition of zinc or manganese to the buffer rather than calcium did not restore superoxide production.

The cytoplasmic ionized calcium in calcium-depleted cells was measured by monitoring Quin 2 fluorescence before and after Con A stimulation. In calcium-depleted cells, the addition of Con A did not cause any alteration in cytoplasmic ionized calcium when the cells were suspended in HBSS without added calcium. The subsequent addition of $1 \mathrm{mM} \mathrm{CaCl}_{2}$ caused an immediate rise in ionized calcium from 30 to $250 \mathrm{nM}$ (Fig. 6).

Superoxide production in human monocytes treated with A23187. Monocytes treated with the calcium ionophore, A23187, also produced superoxide anion (Fig. 7). In the presence of external calcium the rate of anion production increased proportionately with increasing concentrations of A23187 within a narrow range between 10 and $100 \mathrm{nM}$. Further increases in A23187 concentration caused a much smaller increase in superoxide production. Human monocytes responded to A23187 with superoxide production after a $36 \pm 2.0$ second lag time (Table III).

The stimulation of monocytes with A23187 resulted in superoxide production that was dependent on the presence of external calcium. Monocytes suspended in buffer containing 1,000 $\mu \mathrm{M}$ ionized calcium produced superoxide at a rate of $0.89 \mathrm{nmol} /$ $10^{6}$ cells per min when exposed to $250 \mathrm{nM}$ A23187 (Table III). When the same cell populations were washed and resuspended in buffer without calcium ( $6 \mu \mathrm{M}$ ionized calcium), the rate decreased to $0.13 \mathrm{nmol} / 10^{6}$ cells per min. When $10 \mathrm{mM}$ EGTA was added to the HBSS, reducing the ionized calcium to $<0.028$ $\mu \mathrm{M}$, no superoxide production could be detected at 5 or $60 \mathrm{~min}$ of incubation. When the external ionized calcium concentration was restored to $1,000 \mu \mathrm{M}$ superoxide was produced at a rate of $0.23 \mathrm{nmol} / 10^{6}$ cells per min.

Effect of a cytoplasmic calcium buffer on monocyte superoxide production. Monocytes that were incubated with $25 \mu \mathrm{M}$ Quin 2-AM accumulated $\sim 3 \mathrm{mM}$ Quin 2-free acid in the cytoplasm (5). Monocyte superoxide production was unaltered by the presence of this large calcium-buffering capacity (Table IV). Mono-

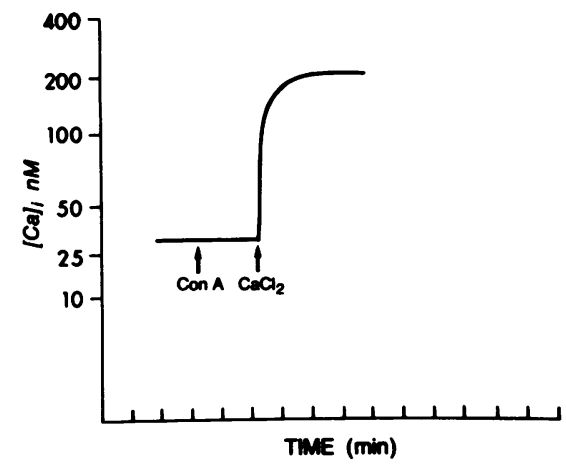

Figure 6. Cytoplasmic ionized calcium in calcium-depleted and repleted human monocytes. Quin 2-loaded monocytes were calcium-depleted by incubation in $10 \mathrm{mM}$ EGTA for $60 \mathrm{~min}$, washed, and resuspended in HBSS with $1 \mathrm{mM}$ Mg. Cytoplasmic ionized calcium was measured by monitoring fluorescence of Quin 2. The exposure of calcium-depleted human monocytes to $100 \mu \mathrm{g} / \mathrm{ml}$ Con A did not increase cytoplasmic ionized calcium. The subsequent addition of $1 \mathrm{mM}$ $\mathrm{CaCl}_{2}$ resulted in a rapid rise in cytoplasmic ionized calcium from 30 to $190 \mathrm{nM}$. The tracing is a representative example of the results in 12 monocyte populations.

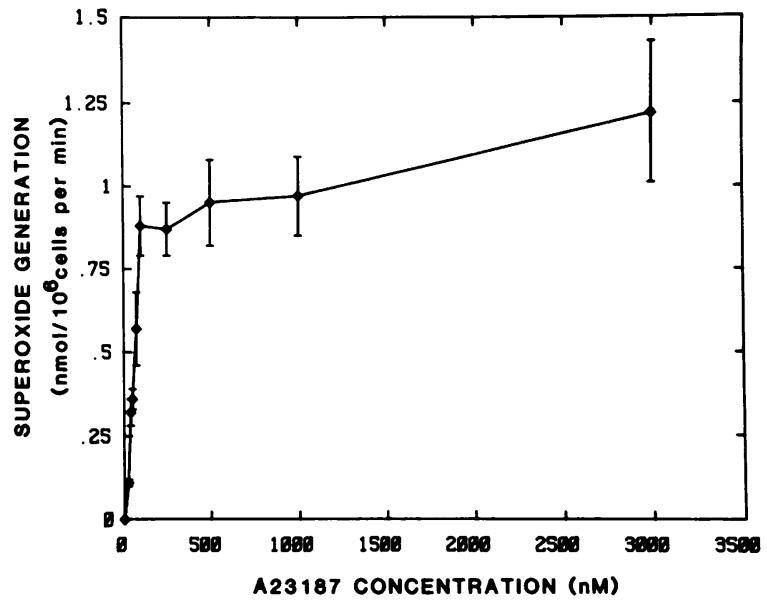

Figure 7. Effect of A23187 concentration on superoxide production. The exposure of monocytes to A23187 stimulated the production of superoxide within $40 \mathrm{~s}$. Superoxide production is expressed in nanomoles $/ 10^{6}$ cells per minute. The addition of $10 \mathrm{mM}$ EGTA prior to A23187 exposure prevented superoxide production. The data represent the mean $\pm \mathrm{SE}$ of three monocyte populations.

cytes loaded with Quin 2 produced superoxide at control rates and with control lag times in the presence either of $1,000 \mu \mathrm{M}$ or of $6 \mu \mathrm{M}$ external calcium. Additionally, Quin 2-loaded monocytes were depleted of calcium in EGTA-containing buffer and subsequently showed an inhibition of superoxide production over a time course similar to control cells. Cytoplasmic Quin 2 did not alter the lag time or magnitude of the Con A-stimulated superoxide production when monocytes were depleted of calcium for $60 \mathrm{~min}$ and resuspended in buffer with $1 \mathrm{mM}$ calcium before Con A treatment (data not shown). However, when superoxide production was initiated by calcium addition after Con A treatment in Quin 2-loaded monocytes, the lag time was $23 \pm 2$ s. This lag time in Quin 2-loaded cells was longer than that observed for calcium-initiated superoxide production in cells without Quin 2, 9 $\pm 1.7 \mathrm{~s}(P<0.05)$ (Table II).

Table III. A23187-induced Superoxide Production by Human Monocytes

\begin{tabular}{|c|c|c|c|}
\hline Incubation conditions & $\begin{array}{l}\text { Extracellular } \\
\text { ionized calcium }\end{array}$ & $\begin{array}{l}\text { Superoxide } \\
\text { production }\end{array}$ & Lag time \\
\hline & $\mu M$ & $\begin{array}{l}\text { nmol } / 10^{6} \\
\text { cells per min }\end{array}$ & $s$ \\
\hline HBSS MgCa & 1,000 & $0.89 \pm 0.021$ & $36 \pm 2.0$ \\
\hline HBSS Mg & 6 & $0.13 \pm 0.024$ & $39 \pm 3.4$ \\
\hline \multicolumn{4}{|l|}{ HBSS MgCa +10 mM EGTA } \\
\hline $5 \mathrm{~min}$ at $37^{\circ} \mathrm{C}$ & $<0.028$ & 0 & - \\
\hline $\begin{array}{l}\text { HBSS } \mathrm{MgCa}+10 \mathrm{mM} \text { EGTA } \\
60 \mathrm{~min} \text { at } 37^{\circ} \mathrm{C} \text { washed and } \\
\text { resuspended in HBSS } \mathrm{Mg}\end{array}$ & $<0.028$ & 0 & - \\
\hline $\begin{array}{l}\text { HBSS } \mathrm{MgCa}+10 \mathrm{mM} \text { EGTA } \\
60 \text { min at } 37^{\circ} \mathrm{C} \text { washed and } \\
\text { resuspended in HBSS }\end{array}$ & & & \\
\hline $\mathrm{MgCa}$ & 1,000 & $0.23 \pm 0.07$ & $32 \pm 11$ \\
\hline
\end{tabular}

$250 \mathrm{nM}$ A23187 was used to induce superoxide anion production in each of the incubation conditions shown. Data are expressed as mean \pm SE of 9 monocyte populations. 
Table IV. Con A-induced Superoxide Production in Quin 2-loaded Human Monocytes

\begin{tabular}{llll}
\hline & $\begin{array}{l}\text { Extracellular } \\
\text { ionized calcium }\end{array}$ & $\begin{array}{l}\text { Superoxide } \\
\text { production }\end{array}$ & Lag time \\
\hline & $\mu M$ & $\begin{array}{l}\text { nmol/10 } \\
\text { cells per min }\end{array}$ & $s$ \\
& 1,000 & $0.48 \pm 0.17$ & $56 \pm 4$ \\
HBSS MgCa & 6 & $0.46 \pm 0.38$ & $58 \pm 6$ \\
HBSS Mg & & & \\
$\begin{array}{l}\text { HBSS MgCa }+10 \mathrm{mM} \text { EGTA } \\
60 \mathrm{~min} \text { at } 37^{\circ} \mathrm{C} \text { washed and } \\
\text { resuspended in HBSS Mg }\end{array}$ & 6 & 0 & - \\
$\begin{array}{l}\text { HBSS MgCa }+10 \mathrm{mM} \mathrm{EGTA} \\
60 \mathrm{~min} \text { at } 37^{\circ} \mathrm{C} \text { washed and }\end{array}$ & & & \\
$\begin{array}{l}\text { resuspended in } \mathrm{HBSS} \mathrm{Mg} \\
\text { Con A, then Ca }\end{array}$ & 1,000 & $0.73 \pm 0.11$ & $23 \pm 2$ \\
\hline
\end{tabular}

$100 \mu \mathrm{g} / \mathrm{ml} \mathrm{Con} A$ was used to induce superoxide anion production in each of the incubation conditions shown. Data are expressed as mean \pm SE of 12 monocyte populations.

Table V compares the response times for superoxide production in Quin 2-loaded monocytes. The first column compares the lag times for not-loaded and Quin 2-loaded cells that were activated by Con A. The presence of Quin 2 in the cytoplasm did not affect the lag time to superoxide production in cells not calcium depleted. When monocytes were depleted of calcium for $60 \mathrm{~min}$ and the calcium was restored, the lag times for Con A-initiated superoxide production were not changed. When monocytes were calcium depleted for $60 \mathrm{~min}$ and treated with Con A, no superoxide production was observed. The addition of calcium resulted in superoxide production with a shortened lag time in unloaded and Quin 2-loaded cells. However, the lag time of $23 \pm 2.0 \mathrm{~s}$ in Quin 2-loaded cells was significantly longer than the lag time in not-loaded cells $(9 \pm 1.7 \mathrm{~s})$.

\section{Discussion}

The production of highly reactive oxygen species is central to the bactericidal process, and cytoplasmic ionized calcium has

Table V. Comparison of the Response Times for Superoxide Production in Quin-2-loaded Monocytes

\begin{tabular}{llll}
\hline & $\begin{array}{l}\text { Not calcium- } \\
\text { depleted } \\
\text { Con A-activated }\end{array}$ & $\begin{array}{l}\text { Calcium-depleted } \\
60 \text { min } \\
\text { calcium-repleted } \\
\text { Con A-activated }\end{array}$ & $\begin{array}{l}\text { Calcium-depleted } \\
60 \text { min } \\
\text { Con A-activated } \\
\text { calcium-repleted }\end{array}$ \\
\hline & $s$ & $s$ & $s$ \\
Not loaded & $58 \pm 3.4$ & $60 \pm 2$ & $9 \pm 1.7$ \\
Quin 2-loaded & $56 \pm 4.0$ & $62 \pm 4$ & $23 \pm 2.0$
\end{tabular}

The lag times are expressed as the mean $\pm \mathrm{SE}$ in seconds of nine monocyte populations. The first column shows the lag times for Con A-activated monocytes. The second column shows the lag times for monocytes treated with $10 \mathrm{mM}$ EGTA for $60 \mathrm{~min}$ at $37^{\circ} \mathrm{C}$, washed, and resuspended in HBSS with $1 \mathrm{mM} \mathrm{Mg}$ and $1 \mathrm{mM} \mathrm{Ca}$ and then activated with Con $A$. The third column shows the lag times for monocytes treated with $10 \mathrm{mM}$ EGTA for $60 \mathrm{~min}$ at $37^{\circ} \mathrm{C}$, washed and resuspended in HBSS with $1 \mathrm{mM} \mathrm{Mg}$ but no Ca. Con A $(100 \mu \mathrm{g} / \mathrm{ml})$ did not lead to superoxide production until $\mathrm{Ca}(1 \mathrm{mM})$ was added. been proposed as a second messenger for signaling and sustaining the generation of these oxygen radicals in neutrophils and monocyte-macrophages. The evidence supporting this proposal includes an increased radiolabeled calcium exchange between medium and neutrophils (23), increased radiolabeled calcium exchange between medium and the cytoplasmic pool of neutrophils (7), monocytes (5), and alveolar macrophages (8), and an increase in cytoplasmic ionized calcium accompanying the production of superoxide in monocytes (5), neutrophils $(4,24)$, peritoneal macrophages (12), and alveolar macrophages (25). Superoxide production in neutrophils evoked by Con $A$ is dependent on the presence of external calcium (6), and is sensitive to inhibitors of intracellular calcium redistribution (9), to calcium channel blockers $(10,11)$, and to cytoplasmic calcium buffering agents (26).

The present report addresses whether an increment in cytoplasmic calcium is required for the initiation of monocyte superoxide production. Six lines of evidence indicate that an increment in free calcium is required for superoxide production in monocytes. First, an increment in internal calcium invariably preceded superoxide production in all circumstances where the cells responded to Con A. Second, only when monocytes were calcium-depleted and the Con A-induced increment in internal calcium was eliminated, was superoxide production fully inhibited. Third, inasmuch as monocytes were depleted of calcium for a prolonged period of time, the residual rate of superoxide production paralleled the residual increment in free calcium. Fourth, when the external calcium was restored to calcium-depleted monocytes that were stimulated with Con A, superoxide production was comparable to that measured in cells that had not been depleted. Fifth, readdition of other divalent cations did not substitute for calcium in this regard, and the chelation of trace ions by histidine had no effect on superoxide production. Sixth, A23187 stimulated the production of superoxide in monocytes in a concentration-dependent fashion, and its effect was dependent on the presence of external calcium.

Both Con A and A23187 stimulate the same NADPH oxidase, although through different pathways (27). Our data suggest that the necessity for a rise in the cytoplasmic ionized calcium is a common element in the activation pathways of both of these agents. Data suggesting that the effect of A23187 on monocyte and macrophage activation is directly mediated by calcium uptake and is specifically calcium-dependent support this interpretation (28).

Additional studies were performed to test the effect of buffering the cytoplasmic calcium on superoxide production. Quin 2 can be used to buffer ionized calcium within the cell. Studies of Quin 2-loaded monocytes showed no diminution of the magnitude of the superoxide response as long as intracellular calcium had not been depleted. Theoretical considerations indicate that in the presence of external calcium, Quin 2-loaded cells would establish a new calcium steady state with a physiologic cytoplasmic ionized calcium. Quin 2-loaded cells would also attenuate alterations in the ionized calcium concentration owing to the large calcium-buffering capacity of the probe. The published data regarding the effect of cytoplasmic calcium buffers is contradictory. The presence of cytoplasmic Quin 2 in neutrophils (13) and in alveolar macrophages under certain conditions (25), and cytoplasmic EGTA in peritoneal macrophages (12) impaired superoxide production to chemotactic peptides while other studies have shown no impairment of superoxide production in neutrophils under these conditions $(14,29)$. In this report Quin 
2-loaded human monocytes exhibited unimpaired superoxide production. This result might be expected because the large transplasma membrane calcium gradient provides virtually unlimited calcium so as to establish a new steady state, despite the large cytoplasmic buffering capacity.

Although our data strongly support a requirement for an increase in the free cytoplasmic calcium to initiate superoxide production in lectin-stimulated human monocytes, it is likely that the calcium signal is necessary, but not sufficient for monocyte activation. The studies of the lag times for the initiation of superoxide production support this contention in three ways. First, if Con A is used to stimulate calcium-depleted monocytes, no superoxide production is observed until the calcium is readded. However, the lag time for the initiation of superoxide production is markedly shortened, suggesting that prior events have transpired after Con A binding to the monocyte membrane, which have primed the cell before the readdition of calcium. Second, in Quin 2-loaded, calcium-depleted cells, the lag time after the readdition of calcium was also shortened. This shortening was not as great as that seen in calcium-depleted unloaded cells. This difference is likely the result of the time required to reestablish a new calcium steady state in Quin 2-loaded cells. Finally, the lag time in A23187-treated cells was approximately one-half that of lectin-treated monocytes. This suggests two possibilities, both of which support the concept that calcium is necessary for superoxide production. First, A23187 accelerates the calcium influx into the cytoplasm causing an earlier ionized calcium increment. Alternatively, stimulation by A23187 may bypass or accelerate other events in the Con A-evoked activation process.

Other studies suggest that under special conditions, specifcally when cells are stimulated by phorbol esters or diacylglycerol, superoxide production occurs without an increment in cytoplasmic free calcium (30). These agents activate protein kinase $\mathrm{C}$, a membrane enzyme that is usually dependent on free calcium for its activity. In some tissues, such as adrenal glomerulosa cells (31), phorbol esters and diacylglycerol appear to increase the affinity of protein kinase $\mathrm{C}$ for calcium, permitting the enzyme to be activated at resting free calcium levels. This can be viewed as a relative increase in free calcium from the point of view of protein kinase $\mathrm{C}$ activation in response to these agents. In neutrophils (14) and monocytes (Scully, S. P., unpublished observations), phorbol esters can stimulate superoxide production in calcium-depleted cells ( $\sim 10-30 \mathrm{nM}$ free calcium). These findings indicate that treatment with phorbol esters represents a unique circumstance in which superoxide can be generated in the face of extremely low cellular free calcium.

Studies conducted at submaximal concentrations of either phorbol esters or diacylglycerol and either A23187 or $N$-formylmethionyl-leucyl-phenylalanine support the requirement for an increment in free calcium for an optimal physiologic response. A synergistic response greater than the response with either agent alone was observed in neutrophils when either phorbol ester or diacylglycerol was combined with ionophore or chemotactic peptides (32-34). These studies suggest that the products of increased phosphoinositol turnover (i.e., diacylglycerol) and increased cytoplasmic free calcium act coordinately to induce a maximal response in superoxide production.

Our observations in human monocytes generally support the studies in other cells, particularly neutrophils. Previous studies suggest that an increment in cytoplasmic ionized calcium is necessary, but not sufficient, to initiate superoxide production
(13). However, there are some inconsistencies in these data. For example, large increments in free calcium induced by ionophores may produce proportionately less superoxide than much smaller increments induced by other stimuli, such as chemotactic peptides (14). This may reflect the differences between the initial non-calcium dependent steps in cells treated with ionophore as compared to other agents which bind to membrane receptors. Also, an increment in ionized calcium may persist in neutrophils cultured in calcium-free buffer, but may not be sufficient to initiate superoxide production (29). Differences in the ionic requirements of neutrophils as compared to monocytes may account for this finding. The EGTA used to reduce the external calcium binds other metals in addition to calcium, and one of these may be essential for neutrophils, but not for monocytes, which do not strictly require trace ions, at least those chelated by histidine.

Taken together, the accumulated data indicate that Con $\mathrm{A}$ binds to the outer surface of the monocyte plasma membrane and initiates a number of steps, some of which have been defined. An increase in the uptake of ${ }^{45} \mathrm{Ca}$ promptly follows Con A treatment and results in an increase in the labeling of the cytoplasmic compartment of human monocytes (5), neutrophils $(23,24)$, and alveolar macrophages $(8,25)$. This calcium redistribution as measured by ${ }^{45} \mathrm{Ca}$ may contribute to the increment in the cytoplasmic ionized calcium as measured by Quin 2. Calcium may also be released from internal stores and contribute to the cytoplasmic free calcium pool (25). Con A treatment may result in increased phospholipid turnover and in the production of inositol triphosphate, which can release calcium from internal stores, as is the case with chemotactic peptides (35-37). This effect may be the mechanism that accounts for the increment in cytoplasmic calcium when the external calcium is acutely reduced to nanomolar levels. Increased phospholipid turnover also results in the production of diacylglycerol, an endogenous activator of protein kinase $\mathrm{C}$. The steps that are penultimate to superoxide production are, as yet, unknown. In at least one way the process is self-regulating, in that the elevated free calcium can accelerate the calcium transport ATPase directly in monocytes (16), lymphocytes (38), macrophages (39), and neutrophils $(40,41)$; calcium is extruded from the cell, and the rise in free calcium is limited.

\section{Acknowledgments}

The authors thank Elizabeth Kearney for her technical assistance.

This work was supported by U. S. Public Health Service grants CA12790 and CA-34691, the University of Rochester Blood Research "Jimmy Fund," and the Charles E. Culpeper Foundation. Dr. Scully was supported by grant T32-GM07356 from the National Institute of General Medical Science.

\section{References}

1. Babior, B. 1984. The respiratory burst of phagocytes. J. Clin. Invest. 73:599-601.

2. Whitin, J. C., C. E. Chapman, E. R. Simons, M. E. Chovaniec, and H. J. Cohen. 1980. Correlation between membrane potential changes and superoxide production in human granulocytes stimulated by phorbol myristate acetate: evidence for defective activation in chronic granulomatous disease. J. Biol. Chem. 255:1874-1878.

3. Kitagawa, S., F. Takaku, and S. Sakamoto. 1980. Evidence that proteases are involved in superoxide production in human polymorphonuclear leukocytes and monocytes. J. Clin. Invest. 65:74-81. 
4. White, J. R., P. Naccache, T. Molski, P. Borgeat, and R. Sha'afi. 1983. Direct demonstration of increased intracellular concentration of free calcium in rabbit and human neutrophils following stimulation by chemotactic factor. Biochim. Biophys. Acta. 113:44-50.

5. Scully, S. P., G. B. Segel, and M. A. Lichtman. 1984. Calcium exchange and ionized cytoplasmic calcium in resting and activated human monocytes. J. Clin. Invest. 74:589-599.

6. Cohen, H. J., J. C. Whitin, M. E. Chovaniec, E. Tape, and E. Simons. 1984. Is activation of the granulocyte by concanavalin A a reversible process? Blood. 63:114-120.

7. Korchak, H., L. Rutherford, and G. Weissmann. 1984. Stimulus response coupling in the human neutrophil kinetic analysis of changes in calcium permeability. J. Biol. Chem. 259:4070-4075.

8. Holian, A., and R. Daniele. 1982. The role of calcium in the initiation of superoxide release from alveolar macrophages. J. Cell. Physiol. 113:87-93.

9. Takeshige, K., T. Mitsumoto, Z. Nabi, and S. Minakami. 1982. Release of membrane calcium and its relation to superoxide formation by polymorphonuclear leukocytes. Adv. Exp. Med. Biol. 141:453-461.

10. Smolen, J., H. Korchak, and G. Wiesmann. 1981. The roles of extracellular and intracellular calcium in lysosomal enzyme release and superoxide anion generation by human neutrophils. Biochim. Biophys. Acta. 677:512-520.

11. Simchowitz, L., and I. Spilberg. 1979. Generation of superoxide radicals by human peripheral neutrophils activated by chemotactic factor: evidence for the role of calcium. J. Lab. Clin. Med. 93:583-593.

12. Hallett, M., and A. Campbell. 1983. Direct measurement of intracellular free $\mathrm{Ca}^{2+}$ in rat peritoneal macrophages: correlation with oxygen radical production. Immunology. 50:487-495.

13. Lew, P., C. Wollhein, F. Waldvogel, and T. Pozzan. 1984. Modulation of cytosolic free calcium transients by change in intracellular calcium buffer capacity: correlation with geocytosis and $\mathrm{O}_{2}^{-}$production in human neutrophils. J. Cell Biol. 99:1212-1220.

14. Pozzan, T., D. Lew, C. Wollheim, and R. Tsien. 1983. Is cytoplasmic ionized calcium regulating neutrophil activation? Science (Wash. DC). 221:1413-1415.

15. Nakagawara, M., K. Takeshige, H. Sumimoto, J. Yoshitake, and S. Minakami. 1984. Superoxide release and intracellular free calcium of calcium-depleted human neutrophils stimulated by $N$-formyl-methionylleucyl-phenylalanine. Biochim. Biophys. Acta. 805:97-103.

16. Scully, S. P., G. B. Segel, and M. A. Lichtman. 1982. Plasma membrane vesicles prepared from unadhered monocytes: characterization of calcium transport and the calcium ATPase. Cell Calcium. 3:515-520.

17. Cohen, H. J., and M. E. Chovaniec. 1978. Superoxide generation by Digitonin-stimulated guinea pig granulocytes: a basis for a continuous assay monitoring superoxide production and for the study of the activation of the generating system. J. Clin. Invest. 61:1088-1096.

18. Lichtman, A. H., G. B. Segel, and M. A. Lichtman. 1979. An ultrasensitive method for the measurement of leukocyte calcium: lymphocytes. Clin. Chim. Acta. 97:107-121.

19. Abboud, C. N., S. P. Scully, A. H. Lichtman, J. K. Brennan, and G. B. Segel. 1984. The requirement for ionized calcium and magnesium in lymphocyte proliferation. J. Cell. Physiol. 122:64-72.

20. Tsien, R., T. Pozzan, and T. Rink. 1982. Calcium homeostasis in intact lymphocytes: cytoplasmic free calcium monitored with a new intracellularly trapped fluorescent indicator. J. Cell Biol. 94:325-334.

21. Gallo, R. L., R. P. Wersto, R. H. Notter, and J. N. Finkelstein. 1984. Lysophosphatidylcholine cell depolarization: increased membrane permeability for use in the determination of cell membrane potentials. Arch. Biochem. Biophys. 235:544-554.

22. Sillen, L. G., and A. E. Martell, editors. 1971. Stability Constants of Metal-Ion Complexes, Supplement 1. The Chemical Society, London. 733-735.
23. Naccache, P., H. Showell, E. Becker, and R. Sha'afi. 1977. Transport of sodium, potassium and calcium across rabbit polymorphonuclear leukocyte membranes: effect of chemotactic factor. J. Cell Biol. 73:428444.

24. Korchak, H., K. Vienne, L: Rutherford, C. Wilkenfeld, M. Finkelstein, and G. Weissmann. 1984. Stimulus response coupling in the human neutrophil temporal analysis of changes in cytosolic calcium and calcium efflux. J. Biol. Chem. 259:4076-4082.

25. Strickle, D., R. Daniele, and A. Holian. 1984. Cytosolic calcium, calcium fluxes and regulation of alveolar macrophage superoxide anion production. J. Cell. Physiol. 121:458-466.

26. Hallett, M., and A. Campbell. 1984. Is intracellular $\mathrm{Ca}^{2+}$ the trigger for oxygen radical production by polymorphonuclear leukocytes? Cell Calcium. 5:1-19.

27. McPhail, L., P. Henson, and R. Johnston. 1981. Respiratory burst enzyme in human neutrophils. J. Clin. Invest. 67:710-716.

28. Onazaki, K., T. Takenawa, Y. Homma, and T. Hashimoto. 1983. The mechanism of macrophage activation induced by $\mathrm{Ca}^{2+}$ ionophore. Cell. Immunol. 75:242-254.

29. Whitin, J. C., K. Takahashi, and H. J. Cohen. 1984. Calcium requirements for activation and reactivation of the human neutrophil $\mathrm{O}_{2}^{-}$generating system. Blood. 64(Suppl. 1):74a. (Abstr.)

30. Fujita, I., K. Irita, K. Takeshige, and S. Minakami. 1984. Diacylglycerol, 1-oleoyl-2-acetyl-glycerol, stimulates superoxide-generation from human neutrophils. Biochem. Biophys. Res. Commun. 120:318 324.

31. Rasmussen, H., I. Kojima, K. Kojima, W. Zawalich, and W. Apfeldorf. 1984. Calcium is an intracellular messenger: sensitivity modulation, C-kinase pathway, and sustained cellular response. Adv. Cyclic Nucleotide Protein Phosphorus. 18:159-193.

32. Robinson, J., J. Budway, M. Karnovsky, and M. Karnovsky. 1984. Superoxide release by neutrophils: Synergistic effects of a phorbol ester and a calcium ionophore. Biochem. Biophys. Res. Commun. 122: 734-739.

33. Penfield, A., and M. Dale. 1984. Synergism between A23187 and 1-oleoyl-2-acetyl-glycol in superoxide production by human neutrophils. Biochem. Biophys. Res. Commun. 125:332-336.

34. Dewald, B., T. Payne, and M. Baggiolin. 1984. Activation of NADPH oxidase of human neutrophils. Potentiation of chemotactic peptide by a diacylglycerol. Biochem. Biophys. Res. Commun. 125:367373.

35. Berridge, M., R. Dawson, C. Downes, J. Heslop, and R. Irvine. 1983. Changes in the levels of inositol phosphates after agonist-dependent hydrolysis of membrane phosphoinositide. Biochem. J. 212:473-482.

36. Burgess, G., J. McKinney, R. Irvine, M. Berridge, P. Irvine, and J. Putney. 1984. Inositol 1,4,5-triphosphate may be a signal for FMLPinduced intracellular Ca mobilization in human leukocytes (HL-60) cells. FEBS (Fed. Eur. Biochem. Soc.) Lett. 176:193-196.

37. Burgess, G., P. Godfrey, J. McKinney, M. Berridge, R. Irvine, and J. Putney. 1984. The second messenger linking receptor activation to internal Ca release in liver. Nature (Lond.). 309:63-66.

38. Lichtman, A. H., G. B. Segel, and M. A. Lichtman. 1981. Calcium transport and calcium ATPase activity in human lymphocyte plasma membrane vesicles. J. Biol. Chem. 256:6148-6154.

39. Lew, P. D., and T. P. Stossel. 1980. Calcium transport by macrophage plasma membranes. J. Biol. Chem. 255:5841-5846.

40. Volpi, M., P. Naccache, and R. Sha'afi. 1980. Calcium transport in inside out membrane vesicles prepared from rabbit neutrophils. $J$. Biol. Chem. 258:4153-4158.

41. Lagast, H., D. Lew, and F. Waldvogel. 1984. Adenosine triphosphate dependent calcium pump in the plasma membrane of guinea pig and human neutrophils. J. Clin. Invest. 73:107-115. 